\title{
Diagnosis and Management of Ataxia-Telangiectasia in Resource-Limited Settings
}

Nienke J.H. van Os ${ }^{1,2}$; Koen J. van Aerde ${ }^{3}$; Judith van Gaalen ${ }^{2}$, Peter J. Merkus ${ }^{4}$, Laura Silveira-Moriyama ${ }^{5,6}$, Tajul A. Tajudin ${ }^{7}$, Bart P.C. van de Warrenburg ${ }^{2}$, Corry M.R. Weemaes ${ }^{3}$, Marieke C. Dekker ${ }^{8}$, Marieke C. Dekker ${ }^{1}$

${ }^{1}$ Department of Pediatric Neurology, Radboudumc Amalia Children's Hospital; Donders Institute for Brain, Cognition and

Behaviour; Radboud university medical center, Nijmegen, The Netherlandsy

${ }^{2}$ Department of Neurology, Donders Institute for Brain, Cognition and Behaviour, Radboud university medical center, Nijmegen, The Netherlands

${ }^{3}$ Department of Pediatrics - Pediatric Infectious Disease and Immunology, Radboudumc Amalia Children's Hospital; Radboudumc Institute for Molecular Life Sciences, Radboud university medical center, Nijmegen, The Netherlands

${ }^{4}$ Department of Pediatrics - Department of Pediatric Pulmonology, Radboudumc Amalia Children's Hospital; Radboud university medical center, Nijmegen, The Netherlands

${ }^{5}$ Department of Neurology, Universidade Estadual de Campinas (UNICAMP), São Paulo, Brazil

${ }^{6}$ Education Unit, UCL Institute of Neurology, University College, London, United Kingdom

${ }^{7}$ Puteri Specialist Hospital, and Sultan Ismail Hospital, Johor, Malaysia

${ }^{8}$ Department of Medicine and Pediatrics, Kilimanjaro Christian Medical Centre, Moshi, Tanzania

Corresponding author: Nienke J.H. van Os, MD;

E-mail: nienke.vanos@ radboudumc.nl.

do) https://doi.org/10.17724/jicna.2020.181

Received: Nov 16, 2019

Accepted: May 26, 2020

Published: May 31, 2020

\begin{abstract}
Ataxia-telangiectasia (A-T) is an autosomal recessive disorder linked to mutations in the ATM gene, and is characterized by neurodegeneration with an early onset cerebellar syndrome, hyperkinetic movement disorders, neuropathy, and oculocutaneous telangiectasia. Immunodeficiency, pulmonary disease, growth failure, diabetes mellitus, increased malignancy risk and hypersensitivity to ionizing radiation complicate the clinical picture. Serum alpha-fetoprotein levels are increased in patients with A-T and can therefore serve as a diagnostic marker for the disease. In resource-limited settings, diagnosis and management of patients with a rare and complex disorder such as A-T may be extremely challenging. This expert opinion-based guideline aims to give a narrative overview of diagnosis and management of A-T in resource-limited settings, by prioritizing different options based on medical necessity, availability, and costs.
\end{abstract}

Kewords: Ataxia-telangiectasia, resource-limited, guideline, multisystem.

(c) Os N.J.H. et al.; licensee JICNA.

\section{BACKGROUND}

Ataxia-telangiectasia (A-T) is a rare, neurodegenerative multisystem disorder with an estimated incidence of 1 in 40,000-100,000 live births [1]. The disease is caused by pathogenic mutations in the A-T mutated $(A T M)$ gene, which plays are role in DNA repair processes and cell cycle control [2]. The neurological picture includes early childhood-onset cerebellar ataxia, with hyperkinetic movement disorders, oculomotor apraxia, and peripheral neuropathy progressively leading to loss of independent walking. Most patients are wheelchair bound around the age of 10 years. Furthermore, A-T is characterized by the presence of nonneurological features that include oculocutaneous telangiectasia, immune deficiency, respiratory tract disease including recurrent sinopulmonary infections, and diabetes mellitus [3]. Patients with A-T have a high risk of developing (mainly hematological) ma- lignancies and are hypersensitive to ionizing radiation and radiomimetic chemotherapeutic drugs. In a nutshell, patients with A-T face a multitude of medical problems caused by disease progression and disease-related complications. Even in those parts of the world where modern, full-facility healthcare systems are available, most patients with A-T will not survive beyond the third decade of life [4]. Milder, or variant, forms of A-T are known, but are rarer than the classic phenotype; these patients often remain undiagnosed for decades [5, 6]. Because of its much higher incidence, and for practical reasons, this paper focuses on the classic form of A-T.

Determination of the global distribution of A-T is challenging since the majority of A-T papers are from resource rich countries in Europe and North America. However, reports from North Africa, the Middle East and Central South Asia imply that A$\mathrm{T}$ also manifests in these areas with a relatively high consan- 
guinity rate. Reports from the most resource-limited parts of the world are scarce $[7,8]$, erroneously suggesting that A-T does not occur in these regions. More logically, A-T must be underreported (and/or underdiagnosed) here, possibly as a result of limited healthcare resources.

Although there is currently no curative therapy for A-T, timely diagnosis is important. Apart from the fact that the diagnosis ends a period of uncertainty and contributes to adequate family counselling, at the same time it increases awareness for the development of secondary problems, such as lung disease or malignancies (which are both major causes of death), and may prevent the exposure to full-dose chemotherapy or ionizing radiation (in both the diagnostic and therapeutic setting). A-T patients are preferably treated by a dedicated multidisciplinary team of experts in the fields of neurology, immunology, pulmonology, oncology and rehabilitation care [9].

The availability and affordability of adequate medical care may be a challenge in resource-limited settings in general, but especially about specialized care for vulnerable groups of patients with complex and rare diseases such as A-T. Lack of healthcare professionals and insurance coverage, unavailability of diagnostic tests and long waiting times, social problems, underdeveloped infrastructures, and poverty are known causes of suboptimal diagnosis and treatment in resource-limited settings $[10,11,12]$. Therefore, hitherto published treatment guidelines for A-T $[9,13,14]$ cannot be implemented worldwide, since these apply to privileged settings with full availability of and access to medical resources. The current guideline aims to give a practical and narrative overview of both the diagnosis and management of A-T in settings where resources are limited and prioritizes different options so individual case-by-case decisions can be based on medical necessity, availability, and costs. We have tried to make an expert opinion-based distinction between 'what can be done' and 'what needs to be done' in order to help health care professionals in resource-limited settings, in particular in secondary to tertiary level hospitals, who are less familiar with A-T.

\section{DIAGNOSIS}

In most countries with limited resources, for example in Sub Saharan Africa, molecular genetic testing for mutations in the ATM gene is unavailable. In countries with access, these services may be unaffordable (e.g., not covered by insurance companies). In addition, genetic counsellors are scarce, and logistic reasons make genetic services difficult to reach for rural persons [15]. A-T, however, can be suspected based on the clinical picture. In cases with a high clinical suspicion of A-T, a presumptive clinical diagnosis can be made using relatively simple and cheap laboratory measures in blood (see below) which can confirm the presence of classic serum abnormalities as well as rule out other disorders that are listed in the differential diagnosis (see Table 1).

\section{Clinical clues}

\section{Neurological features}

A-T needs to be suspected in all children exhibiting cerebellar ataxia that arises when the child begins to walk. Most parents notice clumsiness and frequent falls. Cerebellar ataxia is hardly ever an isolated symptom in A-T, but appears together with hyperkinetic movement disorders such as (mild) choreoathetosis and dystonia. The peripheral nervous system involvement is usually evident by the end of the first decade of life, with the disappearance of tendon reflexes, distal muscle wasting and weakness, and autonomic skin dysfunction at the distal extremities. Anterior horn cell involvement generally emerges at the end stage of the disease. Children with A-T have eye movement abnormalities, ranging from an isolated gaze-evoked nystagmus in younger children to severe oculomotor apraxia in teenagers. Motor abnormalities in A-T are progressive over the years. Importantly, spasticity, epilepsy and intellectual disability are no hallmarks of the disease.

\section{Skin and eye abnormalities}

Almost all A-T patients have telangiectasia, visible in the eyes and sun-exposed skin from the age of approximately four years onwards. Premature ageing (as a feature of defective DNA repair) in children with A-T manifests as (small numbers of) grey hairs and hyper- or hypopigmentation of the skin, already visible in toddlers.

\section{Family history}

A-T is transmitted autosomal recessively and should, therefore, be suspected in families with consanguineous parents or in case of more affected sibs. Furthermore, the prevalence of cancer can be increased in A-T families, as both A-T patients and heterozygous carriers of an ATM mutation have a higher risk of developing malignancies (especially breast cancer) [16].

\section{Malignancies}

Due to defective DNA repair leading to increased risk of malignancy, A-T should be suspected in children with an undiagnosed neurological disability who develop a malignancy.

\section{Laboratory clues}

\section{Alpha-fetoprotein (AFP)}

AFP is considered the most important blood biomarker for A$\mathrm{T}$ since serum levels are increased $(>10 \mathrm{ng} / \mathrm{mL})$ in all patients with classic A-T [17]. Serum AFP levels range from 20 to 1,000 $\mathrm{ng} / \mathrm{mL}$ in A-T [18] and increase with age [19]. Testing the serum AFP level is highly recommended if A-T is suspected. However, its level can be increased in some other ataxia syndromes (that are even rarer than A-T) as well (see Table 1). Since AFP is a fetal 
protein, it is present in high levels in fetal serum, and gradually declines after birth. Therefore, serum AFP levels are physiologically 'elevated' in the first two years of life [18]. The measurement of serum AFP is a relatively simple and affordable blood test.

\section{Liver function}

Serum transaminases (alanine transaminase (ALT) and aspartate transaminase (AST)) can be elevated in A-T patients from puberty onwards $[20,21]$. While these abnormalities are not specific for A-T, and can be a sign of co-infections (that frequently occur in people in resource-limited settings in general), the presence of elevated serum transaminases may give rise to a higher suspicion of this disease. However, these findings need to be placed within the context of additional key clinical or laboratory findings.

\section{Immunology}

Most patients with classic A-T have a combined humoral and cellular immunodeficiency, although variable between patients and during life. If available, laboratory tests may reveal an IgA, IgG or IgG2 subclass deficiency and low numbers of CD4 and CD8 cells in patients with A-T. CD4 testing is often within reach in resource-limited settings where the Human Immunodeficiency Virus (HIV) is prevalent. In some countries, the United States Agency for International Development (USAID) and the World Health Organization (WHO) provide free CD4/8 and HIV viral load testing facilities in the context of HIV treatment. In most cases of A-T, low CD4 numbers are accompanied by lymphopenia, as can be identified by a blood smear. Patients with A-T will also have low antibody responses to pneumococcal polysaccharide vaccines, but these tests may often not be within reach.

Approximately $10 \%$ of patients with A-T have the so-called 'hyper IgM phenotype', resulting from defective class switch recombination, and comprising a serum IgG and IgA deficiency combined with normal to elevated levels of serum IgM. A-T patients with a hyper IgM phenotype have a poor prognosis [4]. An elevated serum IgM level can also be a signal of lymphoma development.

If laboratory tests for the detection of immunodeficiency are not available, the clinical presentation of recurrent sinopulmonary infections combined with neurological features as mentioned above, should raise suspicion of A-T. A report of A-T patients from Mali described frequent diarrhea [7].

\section{Molecular analysis}

If one can rely on contacts with genetic services, ATM gene mutation analysis is the gold standard in the diagnostic work-up of AT. At the protein level, the presence and function of ATM can be analyzed additionally, but there are only a few laboratories worldwide that perform these types of investigations. Cytogenetic analysis, showing chromosomal instability and 7:14 translocations in
A-T, requires other laboratory facilities, is generally expensive, and only offers additional clues to (rather than definite confirmation of) the diagnosis.

\section{Ancillary neurological investigations}

We want to put forward that invasive and expensive diagnostic tests such as electromyography (EMG), magnetic resonance imaging (MRI), lumbar puncture (LP), and electroencephalography (EEG) are unlikely to be cost-effective in the diagnosis of A-T when compared to serum AFP assay, and are not necessary for establishing the diagnosis of A-T. EEG and LP are normal in patients with A-T. MRI and EMG will confirm clinical findings of cerebellar dysfunction (showing unspecific cerebellar atrophy) and peripheral neuropathy (with anterior horn cell involvement in advanced disease), respectively. Although not paramount or sufficient to confirm the diagnosis of A-T, they may be helpful in ruling out other disorders listed in the differential diagnosis (see below) and should be considered on a case-by-case basis. It is important to note that computed tomography (CT) may not only be cost-ineffective, but it is likely to be harmful for cases with a high clinical suspicion of A-T, given the increased radiosensitivity in A-T patients.

\section{Differential diagnosis}

The differential diagnosis of A-T is broad. However, only a few disorders feature a combination of the typical neurological signs and laboratory abnormalities as described above. The other distinctive non-neurological features are crucial to narrow the differential diagnosis.

Patients with A-T may be misdiagnosed with 'ataxic cerebral palsy' (ataxic CP), but careful history taking will be helpful here. Other genetic ataxias such as Friedreich ataxia (FA) (considered the most prevalent autosomal recessive ataxia), ataxia with vitamin E deficiency (AVED), and ataxia with oculomotor apraxia (AOA) types 1, 2, 3 and 4 can be distinguished from A-T by taking into account both clinical and laboratory characteristics, such as pyramidal signs, low serum albumin or increased serum cholesterol levels. The serum AFP levels of patients with AOA are generally lower compared to patients with A-T, and all AOA types are far more rare than A-T (see Table 1). Since certain DNA repair disorders like A-T-like disorder are extremely rare (and serum AFP is not elevated in patients with these disorders), we will not discuss these in more detail.

In case of lack of certainty, acquired causes of ataxia (in childhood), such as alcoholism, vitamin deficiency, vascular abnormalities, infectious disease (e.g. HIV, post-varicella) and auto-immune/demyelinating or (para)neoplastic disease should be ruled out. In many of these acquired disorders, the patient's history as well as a careful physical (including neurological) investigation will be very helpful. To give an example, most acquired causes of ataxia do not have an early childhood onset and are not accompanied by other hyperkinetic movement disorders, develop (sub)acute, and have a more rapid progression 
than A-T. Autosomal dominantly inherited causes of ataxia include spinocerebellar ataxias (SCA), and episodic and spastic ataxias. These disorders should be considered in cases with isolated ataxia, ataxia combined with pyramidal signs and in families where multiple generations are affected. As a rule, serum AFP levels are normal in patients with these forms of ataxia. Klockgether et al. recently published a schematic representation of the global prevalence of SCA subtypes [22].

\section{MANAGEMENT INCLUDING TREATMENT AND FOLLOW-UP}

\section{Avoid ionizing radiation}

Following in the golden rule of "first do no harm", it is imperative to highlight that once a confirmed or presumptive diagnosis of A-T is made, every effort should be made to avoid ionizing radiation, starting with avoidance of diagnostic tests such as X-rays, tomography and nuclear medicine.

\section{Nutrition / endocrinology}

Malnourishment is an unfavorable prognostic factor in general, which leads to increased disease burden and mortality. It is known to play a considerable role in the progression of neurodegenerative diseases [30] and is a major problem in resourcelimited settings [31]. Besides the problem that nutritious foods can be difficult to acquire in resource-limited settings, patients with A-T may have the additional disadvantage that they may physically struggle to eat (due to fatigue, and oral-motor problems affecting swallowing and chewing), and endocrine abnormalities can also impede their growth [32, 33, 34, 35]. Without a good nutritional status, the effectiveness of other symptomatic treatments for A-T will be suboptimal. Therefore, we believe that nutritional problems in A-T should be tackled first.

For patients with other neurological disorders such as cerebral palsy, it is known that in resource-limited settings, malnourishment is augmented by poverty and severity of clinical features $[36,37]$. Adequate nutritional support had a good effect on the nutritional status and body composition of these children [38]. Adequate training and support of caretakers is also found to be of major importance [39, 40].

Practical tips to improve intake are to pay attention to a good sitting position during meals (so that the patient is supported in seating for optimal safe swallowing), use of easy chewable foods or cutting food into bite-sized portions, thickening of thin liquids (although special products to facilitate this may not be easy available everywhere) and the use of a straw [9, 32]. Since fatigue can cause suboptimal oral intake, patients should be rested before they have a meal [32]. If accessible, speech-and language therapists or dieticians may give additional nutritional or feeding advices. Gastrostomy placement may not be easily available in resource-limited settings (or only by laparotomy and not endo- scopic), but protein-enriched food and drinks, or temporary nasogastric tube feeding may be a solution in severe cases of malnourishment and when recovering from infections. It is important to stress out for parents that in these cases the placement is temporary and only to boost recovery.

If patients with A-T survive into adolescence or adulthood, they may develop diabetes mellitus type 2 . We therefore advice regular testing of serum glucose (or HbA1c if available) levels in these cases (see Screening). In case of elevated serum HbA1c levels, nutritional guidance becomes even more important. Oral treatment with metformin is sufficient to treat diabetes in most cases, and insulin resistance only occurs sporadically. The availability and affordability of essential medicines for diabetes may be problematic in resource-limited settings [41].

Low vitamin D levels are common in patients with A-T [33, 35]. Osteoporosis can be a problem in older patients who are wheelchair bound for years [42] and in particular when proper rehabilitation was not provided early. A healthy nutritional status and good dietary calcium intake are important. Supplementation of estrogens, calcium or vitamin D may be effective to prevent fractures.

Other endocrine problems that are reported in A-T, such as hypercholesterolemia, growth hormone deficiency and gonadal failure, generally don't lead to major clinical concerns in A-T, and these features may therefore not require additional diagnostic tests or treatment in resource-limited settings.

\section{Neurology / rehabilitation}

The treatment of neurological features and their complications consists mainly of supportive care, and - in our experience hardly ever necessitates drug therapy. In addition, the effectiveness of pharmacotherapy for movement disorders in A-T is low to moderate; availability may be problematic, while costs may be high. Therefore, we recommend to be mindful to prescribe these. Above that, and even more important, patients generally do not complain about their movement disorder, irrespective of the fact that it leads to impressive reduction of the ability to move independently and necessitates the use of aids including a wheelchair. In our opinion, dystonia is potentially the most troublesome movement disorder in A-T. Dystonia is often present, but the distribution and severity vary substantially between patients. Focal dystonia can be attenuated by botulinum toxin injections, if available. Simple stretching exercises and good use of sensory tricks in rehabilitation will decrease secondary deformity which is common in long standing dystonia.

For generalized dystonia, we recommend a trial with levodopa early on, since some patients with A-T and a dopa-responsive dystonia have been described [43]. If this is not effective, other drugs such as anticholinergics, GABA mimetics, tetrabenazine or gabapentin can be prescribed in order of availability and costs [9] and properly monitored for side effects including cognitive slowing and worsening of axial hypotonia which may predispose to scoliosis. For recommendations regarding the drug treatment of 
Table 1 Differential diagnosis of A-T.

\begin{tabular}{|c|c|c|c|c|c|c|c|}
\hline Disease (gene) & Onset & Increased serum AFP (ng/mL) [18] & Immuno deficiency & Telangiectasia & Malignancy risk & Inheritance & Other distinctive features \\
\hline $\mathrm{A}-\mathrm{T}(A T M)$ & $<2$ years & 19 & + & + & + & AR & See text \\
\hline FA $(F X N)$ & $10-16$ years & - & - & - & - & $\mathrm{AR}$ & $\begin{array}{l}\text { Pyramidal sings, opticopathy, } \\
\text { cardiomyopathy [23] }\end{array}$ \\
\hline AVED (TTPA) & $5-15$ years & - & - & - & - & AR & $\begin{array}{l}\text { Reduced plasma vitamin E } \\
\text { level, visual problems, pyrami- } \\
\text { dal signs [24] }\end{array}$ \\
\hline AOA1 $(A P T X)$ & $2-10$ years & $-/+(<60$, stable $)$ & - & - & - & AR & $\begin{array}{l}\text { Hypoalbuminemia, increased } \\
\text { serum total cholesterol [25] }\end{array}$ \\
\hline AOA2 (SETX) & $3-30$ years & $+(<60$, stable $)$ & - & - & - & AR & Pyramidal signs[26] \\
\hline AOA3 (PIK3R5) & $12-18$ years & $+(<100)$ & - & - & - & AR & $\begin{array}{l}\text { Rare (only } 4 \text { patients in Saudi } \\
\text { Arabian family are described) } \\
\text { [27] }\end{array}$ \\
\hline AOA4 $(P N K P)$ & $<10$ years & $-/+(<60)$ & - & - & - & AR & $\begin{array}{l}\text { Hypoalbuminemia, elevated } \\
\text { cholesterol [28] }\end{array}$ \\
\hline SCA & $\begin{array}{l}\text { Wide range } \\
(25-50 \mathrm{yrs})\end{array}$ & - & - & - & - & $\mathrm{AD}$ & $\begin{array}{l}\text { Pyramidal signs, other features } \\
\text { depending on SCA gene [29] }\end{array}$ \\
\hline Ataxic CP & Neonatal & - & - & - & - & Non genetic & Pyramidal signs, static \\
\hline
\end{tabular}

other neurological symptoms in A-T, such as ataxia, chorea, myoclonus, or tremor, we refer to our previously published treatment guideline [9]. There is limited evidence for successful treatment of oculomotor apraxia and nystagmus, but baclofen, gabapentin or 4-aminopyridine can be tried.

It is well known that in resource-limited settings, the daily care of chronically ill patients is often the responsibility of their family members. It is imperative nevertheless that this care is at least supervised by health care professionals such as physiotherapists, occupational therapists, and speech and language therapists and if available, a rehabilitation specialist. The main goal of these interventions is the maintenance of physical function and condition, and prevention of complications such as contractures or dysphagia. We are aware of the fact that the accessibility of these professionals may vary within and between resource-limited settings; physiotherapists are often most easily accessible. In addition, institutions for children with special needs, or special units at a general school may be very scarce, even as aid devices, such as wheelchairs, standing frames, and ankle-foot orthoses (which can be helpful for the bilateral foot drop that most children develop as a result of peripheral neuropathy). A (wheel)chair that provides a good upright sitting position is essential to reduce scoliosis, choking, and an inadequate cough. Scoliosis decreased pulmonary expansion and further predisposes to pulmonary infection. Respiratory rehabilitation with simple exercise routines should also be implemented with the help of a physiotherapist. Mobile phones can be a helpful tool for communication in patients with a severe dysarthria.

\section{Immunology}

Severe, systemic and opportunistic infections do not generally occur in patients with A-T. The most commonly occurring infections in patients with A-T are mild sinopulmonary infections. Common measures to decrease the occurrence of these infections in resource-limited settings include optimizing physical condition, education, antibiotic (prophylactic) therapy, and adequate vaccinations.
For A-T patients with an immunodeficiency, hygienic regimens to decrease the risk of infections need to be discussed with patients and their families. Furthermore, patients and their families should be made aware of about 'alarm' symptoms (e.g. fever, cough, dyspnea) and should be advised when to contact a doctor.

We believe that in patients with A-T antibiotic treatment should be administered more easily or sooner compared to patients with normal immunological function, in order to prevent a prolonged or severe course of these infections, that can seem mild at first sight. When patients do not improve sufficiently following antibiotic treatment, (myco-)bacterial cultures with resistance results and viral PCRs should be obtained in order to guide further management. For these investigations, sputum or nasal/pharyngeal swabs will suffice. Broncho-alveolar lavage is seldomly indicated.

Prophylactic antibiotic treatment should be considered, if available, in A-T patients with recurrent or severe infections. Amoxicillin (in a single dose of $30 \mathrm{mg} / \mathrm{kg} / \mathrm{day}$ ), Co-trimoxazole (in a single daily dose of $18 \mathrm{mg} / \mathrm{kg}$ ) and Azithromycin (in a single dose of $10 \mathrm{mg} / \mathrm{kg}$ three times a week) are generally used. Side effects and microbiological resistance should be taken into account [14]. Azithromycin has a suggested immunomodulatory effect.

Intravenous immunoglobulin (IVIg) substitution therapy may often not be available nor affordable in resource-limited settings. If periodic IVIg substitution is possible, we believe this is most strongly indicated in patients with a severe immunodeficiency with IgG deficiency $(\operatorname{IgG}<4 \mathrm{~g} / \mathrm{l})$, a hyper IgM phenotype, or in patients with recurrent infections and low specific antibody responses despite booster immunizations [44]. In patients with an isolated $\operatorname{IgA}$ and/or IgG2 deficiency, IVIg is not mandatory and the effects do not outweigh the costs.

HIV positive patients with A-T have not been described in the literature thus far. We assume these patients have a poor prognosis. In case a patient with A-T is found to be HIV positive, we suggest to start antiretroviral therapy as soon as possible. Furthermore, in A-T patients in resource-limited settings with signs of severe (i.e. rather uncommon) immunodeficiency, we advise to search for secondary underlying causes (like HIV). 
Although some exceptions to the rule exist, we advise that all children with A-T should participate in National routine immunization programs. These programs differ per country. In some countries, certain vaccines may be unavailable or only available in the private setting. Routine immunizations that are recommended for all immunization programs by the WHO include vaccines against BCG, Hepatitis B, Polio, Diphtheria, Tetanus, Pertussis, Haemophilus influenzae type b, Pneumococcal conjugates, Rotavirus, Measles, Rubella, and Human Papilloma virus [45]. Most of these vaccines are administered before A-T is even suspected, and this normally goes without trouble or complications. Importantly, inactivated vaccines are safe in all patients with A-T. In A-T patients with a severe immunodeficiency (IgG deficiency or hyper IgM phenotype), the Rubella vaccine is thought to increase the risk for development of granulomas [46, 47]. Of note, cutaneous granulomas may occur in up to $10 \%$ of all patients with A-T [48], and their treatment is extremely challenging [49].

Therefore, we recommend not to give live attenuated vaccines to A-T patients that have a severe immunodeficiency, CD4 cell numbers below $500 / \mathrm{mm} 3$, or lymphopenia, in order to decrease the risk of vaccine-derived complications [50,51], although we are not aware of reports that describe these complications in A-T patients after vaccination. If available, we recommend vaccination with flu vaccine (every year) and 13-valent pneumococcal conjugate and 23-valent pneumococcal polysaccharide vaccines (every five years) in all patients with A-T.

\section{Pulmonology}

Pulmonary involvement is a major, chronic and often progressive feature of A-T. Clinically, pulmonary problems can be suspected in patients with cough, dyspnea, congestion and wheeze [42]. Lung disease in A-T is caused by a combination of recurrent upper and lower respiratory tract infections (as a result of the underlying immunodeficiency), interstitial lung disease/fibrosis, and pulmonary stasis of pathogens and aspiration due to neurological impairments like weakness, abnormal swallowing and breathing, and coughing [14]. Although respiratory infections constitute a very high burden of disease in resource-limited settings, upper and lower respiratory tract infections are rarely severe in A-T and do generally not require intravenous antibiotic treatment or hospitalization. However, their recurrent nature constitutes a permanent threat to the lungs, especially since they are combined with the pulmonary consequences of chronic neurologic disease, immunodeficiency, impaired ability to cough effectively, aspirations, and the presence of intrinsic lung disease. In addition, malnourishment is a significant comorbidity and risk factor for a poor prognosis. Viruses are common pathogens in early childhood, and infections with bacteria such as H. influenzae, S. Pneumoniae, and S. aureus are more common in older children $[52,53]$. As a rule, rare opportunistic infections do not occur in A-T, but recurrent infections contribute to the development and progression of bronchiectasis and progressive loss of lung function. Therefore, prophylactic antibiotics are frequently prescribed on inconsistent and non-evidence-based criteria, and this varies considerably between centers and countries. Interstitial lung disease develops in a minority of patients and if so, usually emerges from adolescence onwards in patients with A-T, and is not a primary concern in young patients with A-T. It should be suspected in older children with respiratory symptoms who do not respond to treatment with antibiotics. Oral corticosteroids may be helpful in these cases [14] but are only effective when administered soon after onset. The emergence of side effects, such as diabetes and osteoporosis, should be monitored [14].

Adequate monitoring of pulmonary structure and function in A$\mathrm{T}$ is a challenge. Given the increased radio sensitivity that all patients with A-T express, lung imaging by X-ray or CT should be avoided when possible, especially if alternative imaging techniques are or become available. Pulmonary auscultation is these patients is easy and cost effective. Modifications of MRI of the lungs for routine patient care is likely available within a few years. Spirometry may be a good alternative that gives insight into the pulmonary status, however, discoordination due to muscle weakness and ataxia will often underestimate true lung function. Compared to other diagnostic tests described here, spirometry is relatively easy accessible and affordable but still not available in all hospitals [54]. In our experience, most patients have a restrictive pattern (explaining a low forced vital capacity), sometimes combined with obstructive pulmonary dysfunction. Obviously, simple clinical observation of heart- and respiratory rates, which may be easily overlooked or underestimated in high-tech environments, provides an impression of the pulmonary status.

\section{Oncology}

Patients with A-T are prone to develop cancer. In children with A$\mathrm{T}$, hematological malignancies such as leukemia and lymphoma occur more frequently than solid tumors. Although the differential diagnosis of anemia in a child in a resource-limited setting is broad, the risk for leukemia or lymphoma in A-T is so high that they should be considered seriously early during the diagnostic workup.

The prognosis of children with A-T and a malignancy is poor. In countries with full facility settings, these patients generally survive only one year after their cancer diagnosis [4], suggesting an even more worrying survival in resource-limited settings. The treatment of malignancies in A-T is complicated by an increased sensitivity for radiation therapy and certain cytostatic drugs, due to the underlying DNA repair defect. In addition, delayed presentation with subsequent advanced disease stage, limited access to diagnosis and treatments, malnourishment (with a higher likelihood of infections, neutropenia and treatment delay) and the presence of a physical handicap will make effective treatment of a malignancy in patients with A-T in resource-limited settings without any doubt extremely difficult $[55,56]$. This is further complicated by the general facts that costs of cancer treatment are often not covered by health insurance [55] (and the majority of patients in resource-limited countries may not be health insured at all), and treatment related mortality and abandonment of treatment occur often in resource-limited settings [57]. 
When a child with A-T is diagnosed with a hematological malignancy, one may consider to consult the International BFM (I-BFM) Genetic Variation Working Group (www.bfminternational.wordpress.com) for their expert opinion, since standard protocols may be far too toxic (and thus life threatening) for patients with A-T, and currently no evidence-based treatment protocols for A-T are available. I-BFM is a global working group doing research on pediatric leukemias and lymphomas. In general, radiotherapy and radiomimetic drugs should be avoided or dosages should be reduced. Additionally, social or financial factors may play a role in the final treatment of choice.

Supportive care should be embedded early in the disease course. This includes social support of patients and parents, optimizing nutritional status, the use of prophylaxis in immunodeficient A-T patients, antiretroviral therapy in patients who are HIV positive, and adequate pain control. In case curative cancer treatment is not possible, which will unfortunately be the case in almost every patient with A-T and cancer in resource-limited settings, palliative care should be initiated timely [55].

\section{Surgery, anesthesia and critical care}

Since multisystemic problems - of pulmonary origin in particular - are common in patients with A-T, mechanical ventilation may be challenging, and patients are at increased risk of peri-and postoperative complications [57]. Therefore, surgery (in a dedicated clinic) should be very well considered in A-T patients in resourcelimited settings, and should only be conducted if chances of recovery and expected quality of life are acceptable. Local anesthesia is preferred, as this is the safest option in resource-limited settings. In order to decrease the risk of adverse outcome, preoperative screening of the pulmonary status is desirable [57] and efforts should be made to keep patients in good nutritional status before and after surgery [58]. Immunodeficient A-T patients would theoretically be more at risk to develop wound infections after surgery [58], so perioperative hygienic measures are of major importance.

\section{Novel therapies}

Although possible novel therapies for A-T in research settings, like gene therapy, will generally be out of reach for patients in resource-limited settings, we feel that we should briefly elaborate on this topic. Gene therapy is on the horizon for A-T, with a first trial ongoing in a single case [59]. Industry-driven trials, such as an ongoing trial exploring the effects of steroid treatment in A-T [60] may be relevant since companies may be willing to extend the trial sites also to those located in resource-poor areas. Finally, simpler and even relatively cheap disease-modifying treatment strategies may become available. As an example, we are currently running a trial to study the effects of nicotinamide riboside (a form of vitamin $\mathrm{B} 3$ ) in $\mathrm{A}-\mathrm{T}$, of which the results will become available at the end of this year [61].

\section{GENETIC COUNSELLING}

Counselling of patients and family members should focus on the fact that A-T is an autosomal recessive disease. Parents must be made aware that they are both likely to be heterozygous carriers of a pathogenic ATM gene mutation, thus with a recurrence risk of A-T of $25 \%$ in (future) siblings of their child with A-T. Furthermore, carriers should be alerted to their own health risks, since heterozygous carriers of a pathogenic ATM mutation are at increased risk to develop (breast) cancer, and cardiovascular diseases [16]. In resource-limited settings, such counselling can be complicated by a lack of knowledge, inaccessibility of genetic services, and by cultural or religious beliefs [62].

\section{SCREENING}

\section{Screening patients}

If possible, we advise annual screening for the development of malignancies, diabetes and liver and pulmonary disease (see Table 2). If annual screening is not possible, close clinical follow-up might be equally effective. Patients and families should be made aware of 'alarming symptoms' such as fever, fatigue, weight loss, spontaneous bleeding and easy bruising, bone pain, and the development of new skin abnormalities or localized pain or swellings. They need to be instructed to contact the doctor if one of these symptoms emerge. Physical examination should additionally focus on the presence of organomegaly and lymphadenopathy. Breast cancer screening in adult female patients is important, but mammography should be avoided because of radiation exposure. The other way around, if a child presents with a malignancy and has a neurological disability as well, the diagnosis of A-T should be seriously considered.

Screening for immunodeficiency should be done every two years, but need to be intensified in case of recurrent infections or abnormal (decreased) IgG levels. Lymphopenia in A-T is generally stable over the years.

\section{Screening carriers}

As mentioned, genetic screening for mutations in the ATM gene is often unavailable in resource-limited settings. Furthermore, if a mutation in a breast cancer susceptibility gene like ATM is found in a family member, this may have unexpected and unwanted consequences like losing employment or insurance coverage [15]. Therefore, we believe that the management of (possible) carriers should focus on early detection of breast (or other) cancer, and on optimal access to treatment rather than on genetic testing for ATM carriership [15]. Importantly, early detection and treatment of breast cancer are most cost effective [63]. Clinical breast examination may be beneficial, and is cheaper than mammography [64]. Furthermore, a healthy lifestyle (without smoking, and including a healthy diet) should be actively promoted by the treating physician [64]. 
Table 2 Routine screening tests in A-T.

\begin{tabular}{|l|l|l|}
\hline Screening for & From age & Tests \\
\hline \multirow{3}{*}{ (Hematological) malignancy } & All ages & Serum LDH, blood count and smear, IgM \\
\cline { 2 - 3 } & Adults & Abdominal ultrasound \\
\cline { 2 - 3 } & Adults & Breast cancer screening (no mammography) \\
\hline \multirow{2}{*}{ Diabetes } & Adults & Serum fasting glucose, HbA1c \\
\cline { 2 - 3 } & Adults & Glycosuria \\
\hline \multirow{2}{*}{ Liver disease } & Adults & Serum transaminases \\
\cline { 2 - 3 } & Adults & Abdominal ultrasound \\
\hline Pulmonary disease & Children who are capable of spirometry & Lung function test (no X-ray or CT) \\
\hline Immunodeficiency & All ages & IgG, white blood cell count \\
\hline
\end{tabular}

Table 3 Clinical implications.

\begin{tabular}{|c|c|}
\hline \multirow{9}{*}{ What to do (in all patients) } & Diagnostic test: serum AFP level \\
\hline & Improve nutritional status \\
\hline & $\begin{array}{l}\text { Increase condition and prevent compli- } \\
\text { cations with therapy and aid devices }\end{array}$ \\
\hline & Follow national vaccination programs \\
\hline & $\begin{array}{l}\text { Early treatment of infections to prevent } \\
\text { complications }\end{array}$ \\
\hline & $\begin{array}{l}\text { Early palliative care in case of malig- } \\
\text { nancy }\end{array}$ \\
\hline & Counselling of families \\
\hline & Plan annual visits \\
\hline & $\begin{array}{l}\text { Give information about alarming } \\
\text { symptoms }\end{array}$ \\
\hline \multirow[t]{4}{*}{ What can be done (in some patients, if indicated) } & $\begin{array}{l}\text { Pharmacotherapy for movement disor- } \\
\text { ders seems only relevant in the case of } \\
\text { dystonia }\end{array}$ \\
\hline & $\begin{array}{l}\text { Prophylactic antibiotics, only if recur- } \\
\text { rent or severe (bacterial) infections oc- } \\
\text { cur }\end{array}$ \\
\hline & $\begin{array}{l}\text { Intravenous immunoglobulins, only if } \\
\text { indicated by proven deficiencies with } \\
\text { clinical consequences }\end{array}$ \\
\hline & $\begin{array}{l}\text { Genetic testing for carriers, only if pos- } \\
\text { sible }\end{array}$ \\
\hline \multirow[t]{2}{*}{ What not to do } & $\begin{array}{l}\text { Expensive and invasive diagnostic tests } \\
\text { (MRI, EEG, EMG, LP) should not } \\
\text { be done without proper indication and } \\
\text { only to rule out broad differential diag- } \\
\text { nosis }\end{array}$ \\
\hline & $\begin{array}{l}\text { Exposure to ionizing radiation (CT, } \\
\text { X-ray, radiation therapy, radiomimetic } \\
\text { drugs) should be limited to last re- } \\
\text { source, and dose can be adapted }\end{array}$ \\
\hline
\end{tabular}




\section{CONCLUSIONS AND FINAL REMARKS}

A lack of health care professionals, let alone pediatricians and neurologists, combined with a lack of knowledge on A-T, make adequate diagnosis and treatment of A-T in resource-limited settings challenging. This paper gives a practical overview of diagnostic and therapeutic options in such situations and gives expert opinion-based recommendations about 'what needs to be done', 'what can be done' and 'what not to do' (see Table 3), in the fields of nutrition, neurology, immunology, pulmonology and oncology. Our key messages are listed below. Obviously, we and other 'A-T groups' around the world, including families and patients with A$\mathrm{T}$ as well as health care professionals, are available for advice via websites and email (ataxia-telangiectasia@radboudumc.nl). Detailed information about A-T and the opportunity to contact other families in English, is possible via the websites of the 'A-T Society' (www.atsociety.org.uk), and the 'A-T Children's Project' (www.atcp.org).

\section{KEY MESSAGES}

In resource-limited settings one should know that:

1. The occurrence of A-T is likely severely underreported in many parts of the world due to lack of specialized health care professionals such as pediatricians and neurologists.

2. When a child presents with clinical clues of A-T, serum AFP assessment is sufficient to make a presumptive diagnosis of A-T.

3. High clinical suspicion or a presumptive diagnosis should prompt avoidance of diagnostic tests using ionizing radiation (x-rays, tomography, nuclear medicine).

4. A good nutritional status is very important to prevent complications of the disease.

5. Neurological symptoms generally do not improve with drug treatment; only severe dystonia may necessitate pharmacologic intervention.

6. Recurrent infections is one of the hallmarks of A-T. Prophylactic antibiotic therapy and immunoglobulin substitution therapy are indicated in some, but not in all, cases.

7. Patients with A-T should participate in regular national vaccination programs, but some patients should better not receive live attenuated vaccines.

8. Screening for malignancy, diabetes and pulmonary dysfunction should be performed routinely.

9. When a child develops a malignancy, the prognosis is very poor and palliative care should be implemented.

10. Counselling of families is important for future family planning and to increase awareness of health problems for both patients and their family members.

\section{Acknowledgments}

We want to thank the Twan Foundation (Veenendaal, the Netherlands) for their (financial) support. We want to thank our colleagues from the multidisciplinary A-T team from the Radboud university medical center (Nijmegen, the Netherlands): Marjo van Gerven, Helma Hijdra, Anjo Janssen, Michiel Schoenaker, Riet Strik-Albers, and Stefanie Veenhuis.

\section{Competing interests}

This work was financially supported by a grant of the Twan Foundation, a Dutch patient organization. The funder did not have any role in the writing process of this paper, or the decision if and when to submit for publication. BvdW receives research support from ZonMW, Hersenstichting, Radboud university medical center, and Bioblast Pharma. The authors declare that they have no competing interests.

\section{Authors' contributions}

All authors contributed to revising the work critically for important intellectual content and gave approval for the final version of the manuscript. $\mathrm{NvO}, \mathrm{CW}$, and $\mathrm{MW}$ conceptualized and designed the study and wrote the manuscript.

This is an Open Access article distributed under the terms of the Creative Commons Attribution License which permits unrestricted use, distribution, and reproduction in any medium, provided the original work is properly credited. The Creative Commons Public Domain Dedication waiver applies to the data made available in this article, unless otherwise stated. 


\section{Cite this article as:}

van Os, N. J., van Aerde, K. J., van Gaalen, J., Merkus, P. J., Silveira-Moriyama, L., Tajudin, T. A., van de Warrenburg, B. P., Weemaes, C. M., Dekker, M. C., \& Willemsen, M. A. (2020). Diagnosis and Management of Ataxia-Telangiectasia in ResourceLimited Settings. Journal of the International Child Neurology Association, 1(1). https://doi.org/10.17724/jicna.2020.181

\section{References}

[1] Swift M, Morrell D, Cromartie E, Chamberlin AR, Skolnick MH, Bishop DT. The incidence and gene frequency of ataxia-telangiectasia in the United States. American journal of human genetics. 1986 Nov;39(5):573-583. PublMed.

[2] Savitsky K, Bar-Shira A, Gilad S, Rotman G, Ziv Y, Vanagaite L, et al. A single Ataxia Telangiectasia gene with a product similar to PI-3 kinase. Science (New York, NY). 1995 07;268:1749-53. PublMed.

[3] Sedgwick RP, Boder E. Ataxia-Telangiectasia. In: J Vinken GWB, Klawans H, editors. Handbook of Clinical Neurology. vol. 1. 1st ed. New York, USA: Elsevier; 1991. p. 347393.

[4] van Os NJH, Jansen AFM, van Deuren M, Haraldsson A, van Driel NTM, Etzioni A, et al. Ataxia-telangiectasia: Immunodeficiency and survival. Clinical Immunology. 2017 May;178:45-55. PublMed.

[5] van Os NJH, Hensiek A, van Gaalen J, Taylor AMR, van Deuren M, Weemaes CMR, et al. Trajectories of motor abnormalities in milder phenotypes of ataxia telangiectasia. Neurology. 2018;92(1):e19-e29. Publmed.

[6] Verhagen MMM, Abdo WF, Willemsen MAAP, Hogervorst FBL, Smeets DFCM, Hiel JAP, et al. Clinical spectrum of ataxia-telangiectasia in adulthood. Neurology. 2009;73(6):430-437. PublMed.

[7] Landouré G, Mochel F, Meilleur K, Ly M, Sangaré M, Bocoum N, et al. Novel mutation in the ATM gene in a Malian family with ataxia telangiectasia. Journal of Neurology. 2012;260(1):324-326. PublMed.

[8] Wagstaff LA, Joffe R. Ataxia-telangiectasia in a South African Bantu child. South African Medical Journal. 1969;43(21):662-664. Publimed.

[9] van Os NJH, Haaxma CA, van der Flier M, Merkus PJFM, van Deuren M, de Groot IJM, et al. Ataxia-telangiectasia: recommendations for multidisciplinary treatment. Developmental Medicine \& Child Neurology. 2017;59(7):680-689. Publaled.

[10] Dekker MCJ, Urasa SJ, Howlett WP. Neurological letter from Kilimanjaro. Practical Neurology. 2017;17(5):412416. PublMimed.
[11] McLane HC, Berkowitz AL, Patenaude BN, McKenzie ED, Wolper E, Wahlster S, et al. Availability, accessibility, and affordability of neurodiagnostic tests in 37 countries. Neurology. 2015;85(18):1614-1622. PublMed.

[12] Bower JH, Zenebe G. Neurologic services in the nations of Africa. Neurology. 2005;64(3):412-415. PublMed.

[13] Schoenaker MHD, Suarez F, Szczepanski T, Mahlaoui N, Loeffen JL. Treatment of acute leukemia in children with ataxia telangiectasia (A-T). European Journal of Medical Genetics. 2016;59(12):641-646. PublMed.

[14] Bhatt JM, Bush A, van Gerven M, Nissenkorn A, Renke M, Yarlett L, et al. ERS statement on the multidisciplinary respiratory management of ataxia telangiectasia. European Respiratory Review. 2015;24(138):565-581. PublMed.

[15] Yip CH, Evans DG, Agarwal G, Buccimazza I, Kwong A, Morant R, et al. Global Disparities in Breast Cancer Genetics Testing, Counselling and Management. World Journal of Surgery. 2019;43(5):1264-1270. PublMed.

[16] van Os NJH, Roeleveld N, Weemaes CMR, Jongmans MCJ, Janssens GO, Taylor AMR, et al. Health risks for ataxiatelangiectasia mutated heterozygotes: a systematic review, meta-analysis and evidence-based guideline. Clinical Genetics. 2016;90(2):105-117. PublMed.

[17] Waldmann T, Mcintire KR. SERUM-ALPHAFETOPROTEIN LEVELS IN PATIENTS WITH ATAXIATELANGIECTASIA. The Lancet. 1972;300(7787):11121115. PublMed.

[18] Schieving JH, de Vries M, van Vugt JMG, Weemaes C, van Deuren M, Nicolai J, et al. Alpha-fetoprotein, a fascinating protein and biomarker in neurology. European Journal of Paediatric Neurology. 2014;18(3):243-248. PublMed.

[19] Stray-Pedersen A, Borresen-Dale AL, Paus E, Lindman CR, Burgers T, Abrahamsen TG. Alpha fetoprotein is increasing with age in ataxia-telangiectasia. European Journal of Paediatric Neurology. 2007;11(6):375-380.

[20] Weiss B, Krauthammer A, Soudack M, Lahad A, Sarouk I, Somech R, et al. Liver Disease in Pediatric Patients With Ataxia Telangiectasia. Journal of Pediatric Gastroenterology and Nutrition. 2016 Apr;62(4):550-555. PublMed.

[21] Paulino TL, Rafael MN, Hix S, Shigueoka DC, Ajzen SA, Kochi C, et al. Is age a risk factor for liver disease and metabolic alterations in ataxia Telangiectasia patients? Orphanet Journal of Rare Diseases. 2017;12(1). PublMed.

[22] Klockgether T, Mariotti C, Paulson HL. Spinocerebellar ataxia. Nature Reviews Disease Primers. 2019;5(1). PublMed.

[23] Cook A, Giunti P. Friedreich's ataxia: clinical features, pathogenesis and management. British Medical Bulletin. 2017;124(1):19-30. PublMed. 
[24] Schuelke. M P Adam ea, editor. Ataxia with Vitamin E Deficiency, in GeneReviews $((R))$. University of Washington, Seattle; 1993. hhttps://www.ncbi.nlm.nih.gov/books/ NBK1241/.

[25] Shimazaki H, Takiyama Y, Sakoe K, Ikeguchi K, Niijima $\mathrm{K}$, Kaneko J, et al. Early-onset ataxia with ocular motor apraxia and hypoalbuminemia: The aprataxin gene mutations. Neurology. 2002;59(4):590-595. PublMed.

[26] Moreira, M C and M Koenig. University of Washington SSW, editor. Ataxia with Oculomotor Apraxia Type 2, in GeneReviews $((R))$. University of Washington, Seattle: Seattle (WA).; 1993.

[27] Tassan NA, Khalil D, Shinwari J, Sharif LA, Bavi P, Abduljaleel Z, et al. A missense mutation in PIK3R5 gene in a family with ataxia and oculomotor apraxia. Human Mutation. 2011;33(2):351-354. PublMed.

[28] Bras J, Alonso I, Barbot C, Costa MM, Darwent L, Orme T, et al. Mutations in PNKP Cause Recessive Ataxia with Oculomotor Apraxia Type 4. The American Journal of Human Genetics. 2015;96(3):474-479. Publ Med.

[29] Sun YM, Lu C, Wu ZY. Spinocerebellar ataxia: relationship between phenotype and genotype - a review. Clinical Genetics. 2016;90(4):305-314. PublMed.

[30] Tsagalioti E, Trifonos C, Morari A, Vadikolias K, Giaginis C. Clinical value of nutritional status in neurodegenerative diseases: What is its impact and how it affects disease progression and management? Nutritional Neuroscience. 2016;21(3):162-175. PublMed.

[31] Black RE, Allen LH, Bhutta ZA, Caulfield LE, de Onis M, Ezzati M, et al. Maternal and child undernutrition: global and regional exposures and health consequences. The Lancet. 2008;371(9608):243-260. PublMed.

[32] Ross LJ, Capra S, Baguley B, Sinclair K, Munro K, Lewindon $\mathrm{P}$, et al. Nutritional status of patients with ataxiatelangiectasia: A case for early and ongoing nutrition support and intervention. Journal of Paediatrics and Child Health. 2015;51(8):802-807. PublMed.

[33] Ehlayel M, Soliman A, Sanctis V. Linear growth and endocrine function in children with ataxia telangiectasia. Indian Journal of Endocrinology and Metabolism. 2014;18(7):93. Available from: https://doi.org/10.4103/ 2230-8210.145079.

[34] Lefton-Greif MA, Crawford TO, Winkelstein JA, Loughlin GM, Koerner CB, Zahurak M, et al. Oropharyngeal dysphagia and aspiration in patients with ataxia-telangiectasia. The Journal of Pediatrics. 2000;136(2):225-231. Publ Med.

[35] Nissenkorn A, Levy-Shraga Y, Banet-Levi Y, Lahad A, Sarouk I, Modan-Moses D. Endocrine abnormalities in ataxia telangiectasia: findings from a national cohort. Pediatric Research. 2016;79(6):889-894. PublMed.
[36] Johnson A, Gambrah-Sampaney C, Khurana E, Baier J, Baranov E, Monokwane B, et al. Risk Factors for Malnutrition Among Children With Cerebral Palsy in Botswana. Pediatric Neurology. 2017;70:50-55. PublMed.

[37] Jahan I, Muhit M, Karim T, Smithers-Sheedy H, Novak I, Jones $\mathrm{C}$, et al. What makes children with cerebral palsy vulnerable to malnutrition? Findings from the Bangladesh cerebral palsy register (BCPR). Disability and Rehabilitation. 2018;41(19):2247-2254. PublMed.

[38] Vásquez-Garibay EM. EL APOYO NUTRICIO INTENSIVO MEJORA EL ESTADO NUTRICIO Y LA COMPOSICIÓN. NUTRICION HOSPITALARIA. 2014 Apr;29(4):838-843. PublMed.

[39] Polack S, Adams M, O'banion D, Baltussen M, Asante $\mathrm{S}$, Kerac M, et al. Children with cerebral palsy in Ghana: malnutrition, feeding challenges, and caregiver quality of life. Developmental Medicine \& Child Neurology. 2018;60(9):914-921. PublMed.

[40] Zuurmond M, O'Banion D, Gladstone M, Carsamar S, Kerac M, Baltussen M, et al. Evaluating the impact of a community-based parent training programme for children with cerebral palsy in Ghana. PLOS ONE. 2018 Sep;13(9):e0202096. Available from: https://doi.org/10. 1371/journal.pone.0202096.

[41] Chow CK, Ramasundarahettige C, Hu W, AlHabib KF, Avezum A, Cheng X, et al. Availability and affordability of essential medicines for diabetes across high-income, middle-income, and low-income countries: a prospective epidemiological study. The Lancet Diabetes \& Endocrinology. 2018;6(10):798-808. Publimed.

[42] Rothblum-Oviatt C, Wright J, Lefton-Greif MA, McGrathMorrow SA, Crawford TO, Lederman HM. Ataxia telangiectasia: a review. Orphanet Journal of Rare Diseases. 2016 Nov;11(1). PublMed.

[43] Charlesworth G, Mohire MD, Schneider SA, Stamelou M, Wood NW, Bhatia KP. Ataxia telangiectasia presenting as dopa-responsive cervical dystonia. Neurology. 2013 Aug;81(13):1148-1151. PublMed. Available from: https: //doi.org/10.1212/wnl.0b013e3182a55fa2.

[44] Davies EG. Update on the management of the immunodeficiency in ataxia-telangiectasia. Expert Review of Clinical Immunology. 2009 Sep;5(5):565-575. PublMed.

[45] Organization WH. World Health Organization recommendations for routine immunization - summary tables; 26 April 2019. Available from: https://www.who.int/immunization/ policy/immunization_tables/en/.

[46] Bodemer C, Sauvage V, Mahlaoui N, Cheval J, Couderc T, Leclerc-Mercier $\mathrm{S}$, et al. Live rubella virus vaccine longterm persistence as an antigenic trigger of cutaneous granulomas in patients with primary immunodeficiency. Clinical 
Microbiology and Infection. 2014 Oct;20(10):O656-O663. Publimed.

[47] Buchbinder D, Hauck F, Albert MH, Rack A, Bakhtiar $\mathrm{S}$, Shcherbina A, et al. Rubella Virus-Associated $\mathrm{Cu}-$ taneous Granulomatous Disease: a Unique Complication in Immune-Deficient Patients, Not Limited to DNA Repair Disorders. Journal of Clinical Immunology. 2019 Jan;39(1):81-89. PublMed.

[48] Chiam LYT, Verhagen MMM, Haraldsson A, Wulffraat N, Driessen GJ, Netea MG, et al. Cutaneous Granulomas in Ataxia Telangiectasia and Other Primary Immunodeficiencies: Reflection of Inappropriate Immune Regulation? Dermatology. 2011;223(1):13-19. PublMed.

[49] Woelke S, Valesky E, Bakhtiar S, Pommerening H, Pfeffermann LM, Schubert R, et al. Treatment of Granulomas in Patients With Ataxia Telangiectasia. Frontiers in Immunology. 2018 Sep;9.

[50] Sarmiento JD, Villada F, Orrego JC, Franco JL, TrujilloVargas CM. Adverse events following immunization in patients with primary immunodeficiencies. Vaccine. 2016 Mar;34(13):1611-1616. PublMed.

[51] Heiman S, Weil M, Shulman LM, Simon AJ, Lev A, Somech R, et al. Co-appearance of OPV and BCG vaccinederived complications in two infants with severe combined immunodeficiency. Immunologic Research. 2018 May;66(3):437-443. PublMed.

[52] Schroeder SA, Zielen S. Infections of the respiratory system in patients with ataxia-telangiectasia. Pediatric Pulmonology. 2013 Jun;49(4):389-399. PublMed.

[53] Bhatt JM, Bush A. Microbiological surveillance in lung disease in ataxia telangiectasia. European Respiratory Journal. 2014 Feb;43(6):1797-1801.

[54] Kibirige D, Kampiire L, Atuhe D, Mwebaze R, Katagira W, Muttamba W, et al. Access to affordable medicines and diagnostic tests for asthma and COPD in sub Saharan Africa: the Ugandan perspective. BMC Pulmonary Medicine. 2017 Dec;17(1). PublMed.

[55] Molyneux E, Scanlan T, Chagaluka G, Renner L. Haematological cancers in African children: progress and challenges. British Journal of Haematology. 2017 Jun;177(6):971-978. PublMed.

[56] Israels T, Renner L, Hendricks M, Hesseling P, Howard S, Molyneux E. SIOP PODC: Recommendations for supportive care of children with cancer in a low-income setting. Pediatric Blood \& Cancer. 2013 Feb;60(6):899-904. Publ(med.

[57] Verhagen MMM, Yntema JB, Weemaes CMR, Willemsen MAAP, Verhagen MMM, van Deuren M, et al. AtaxiaTelangiectasia and mechanical ventilation: A word of caution. Pediatric Pulmonology. 2009 Jan;44(1):101-102.
PublMed. Available from: https://doi.org/10.1002/ppul. 20957.

[58] Lockman JL, Iskander AJ, Bembea M, Crawford TO, Lederman HM, McGrath-Morrow S, et al. Anesthetic and perioperative risk in the patient with Ataxia-Telangiectasia. Pediatric Anesthesia. 2011 Nov;22(3):256-262. PublMed.

[59] Ataxia Telangiectasia Children's Project website - A-T child and oligo selected for aso gene therapy; 26 June 2019. https://www.atcp.org/ a-t-child-and-oligo-selected-for-aso-gene-therapy/.

[60] Ataxia Telangiectasia Treatment with the EryDex System; 26 June 2019. http://attest-trial.com/.

[61] ClinicalTrials.gov - Effects of Vitamin B3 in Patients with Ataxia Telangiectasia; 26 June 2019. https://clinicaltrials.gov/ct2/show/NCT03962114?cond= Ataxia-telangiectasia\&rank $=10$.

[62] Zhong A, Darren B, Loiseau B, He LQB, Chang T, Hill J, et al. Ethical, social, and cultural issues related to clinical genetic testing and counseling in low- and middle-income countries: a systematic review. Genetics in Medicine. 2018 Aug. PublMed.

[63] Groot RBCAUdGBOA M T, Hortobagyi GN. Costs and health effects of breast cancer interventions in epidemiologically different regions of Africa, North America, and Asia. Breast Journal. 2006;12(Suppl 1):S81-90.

[64] Gyawali B, Shimokata T, Honda K, Tsukuura H, Ando Y. Should low-income countries invest in breast cancer screening? Cancer Causes \& Control. 2016 Sep;27(11):13411345. Publ Med. 